\title{
Skrining retinopati hipertensi di layanan kesehatan primer di Palembang
}

\author{
Ramzi Amin*, Petty Purwanita, Riani Erna, Prima Maya Sari, \\ Eka Rahmadini, Vidya Hestika
}

Program Studi Kesehatan Mata, Fakultas Kedokteran, Universitas Sriwijaya, Palembang, Indonesia

E-mail : ramziamin@fk.unsri.ac.id

\begin{abstract}
Abstrak
Hipertensi merupakan suatu kondisi dimana pembuluh darah mempunyai tekanan yang tinggi. Retinopati hipertensi merupakan salah satu komplikasi hipertensi. Prevalensi retinopati hipertensi bervariasi antara 2\%15\%. Data di Indonesia mengenai prevalensi retinopati hipertensi masih minim. Untuk identifikasi dan penegakan diagnosis retinopati hipertensi, dibutuhkan kompetensi seorang dokter spesialis mata. Umumnya dokter spesialis mata tidak banyak ditugaskan di layanan kesehatan primer. Sehingga untuk kasus hipertensi yang dapat diselesaikan di layanan primer seperti Puskesmas, angka retinopati hipertensi yang sesungguhnya tidak diketahui. Selain itu kesadaran pasien yang kurang mengenai pentingnya melakukan pemeriksaan mata secara rutin juga menyebabkan prevalensi retinopati hipertensi tidak diketahui. Penelitian ini bertujuan untuk mendeteksi retinopati hipertensi pada pasien hipertensi yang berobat ke Puskesmas di Palembang, yaitu Puskesmas Dempo dan Merdeka. Pemeriksaan dilakukan pada 150 pasien hipertensi. Didapatkan 15,3\% pasien dengan retinopati hipertensi dimana $10 \%$ dengan riwayat hipertensi lebih dari 5 tahun dan 5,3\% dengan riwayat hipertensi kurang dari 5 tahun. Dapat disimpulkan bahwa terdapat pasien dengan retinopati hipertensi yang tidak terdiagnosis di masyarakat. Peran Puskesmas untuk merujuk pasien dengan hipertensi ke dokter spesialis mata sangat penting agar kasus retinopati hipertensi dapat segera terdeteksi.
\end{abstract}

Kata kunci: Hipertensi, Retinopati Hipertensi, Layanan Kesehatan Primer

\begin{abstract}
Hypertensive retinopathy screening at primary health care in Palembang. Hypertension is a condition of blood vessels that have high pressure. Hypertensive retinopathy is a complication of hypertension. The prevalence of hypertensive retinopathy varies between $2 \%-15 \%$. There was lack of data regarding the prevalence of hypertensive retinopathy in Indonesia. Hypertensive retinopathy identification and diagnosis should be performed by an ophthalmologist. Most ophthalmologists are not assigned to primary health care. So that for cases of hypertension that can be resolved at primary health care such as Puskesmas, the true rate of hypertensive retinopathy is unknown. In addition, the patient's lack of awareness about routine eye examinations also causes the prevalence of hypertensive retinopathy to be unknown. This study aims to examine hypertensive retinopathy in hypertensive patients who are attending Puskesmas in Palembang, namely Puskesmas Dempo and Merdeka. The examination was carried out on 150 hypertensive patients. There were 15,3\% patients with hypertensive retinopathy of which $10 \%$ had a history of hypertension more than 5 years and 5,3\% less than 5 years. It could be argued that there are patients with hypertensive retinopathy who were undiagnosed in the community. The role of the Puskesmas in referring patients with hypertension to an ophthalmologist is very important so that the cases of hypertensive retinopathy could be detected immediately.
\end{abstract}

Keywords: Hypertension, Hypertensive Retinopathy, Primary Health Care 


\section{PENDAHULUAN}

Hipertensi dikenal juga sebagai tekanan darah yang meningkat atau tinggi, adalah kondisi dimana pembuluh darah mempunyai tekanan yang selalu tinggi. Tekanan darah dibentuk oleh tekanan darah yang menekan dinding pembuluh darah (arteri). Diagnosis hipertensi atau tekanan darah tinggi ditegakkan bila tekanan darah sistolik $\geq 140 \mathrm{mmHg}$ dan atau

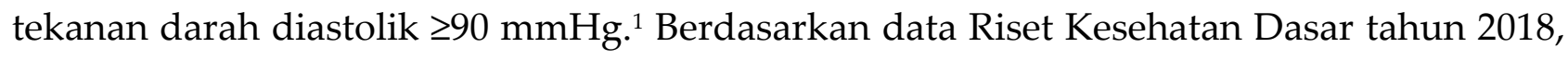
didapatkan prevalensi hipertensi di Indonesia adalah 34,1\%. Persentase ini meningkat dari tahun 2013 yang hanya sebesar $25,8 \% .^{2}$

Peningkatan tekanan darah yang berlangsung lama dan persisten dapat menimbulkan komplikasi di jantung, ginjal, otak dan mata. Pemeriksaan funduskopi merupakan pemeriksaan non-invasif yang dapat membantu melihat perkembangan penyakit pasien apakah sudah terdapat komplikasi ke mata. ${ }^{3}$ Pada umumnya pasien dengan retinopati hipertensi grade awal tidak menunjukkan gejala. Namun jika hipertensi tidak terkontrol dalam waktu lama gejala yang dikeluhkan pasien dapat fatal. Hipertensi maligna akut dapat menyebabkan nyeri pada mata, sakit kepala dan tajam penglihatan yang menurun. Perubahan arteriosklerotik kronis akibat hipertensi tidak akan menyebabkan suatu gejala tunggal. Komplikasi perubahan arteriosklerotik akibat hipertensi dapat menimbulkan gejala oklusi vaskular atau makroaneurisma. ${ }^{3,4}$

Hipertensi merupakan masalah yang sering ditemukan pada pelayanan kesehatan primer. Sampai saat ini pengontrolan hipertensi belum adekuat meskipun obat-obatan yang efektif banyak tersedia. Hal ini dipengaruhi banyak faktor, baik dari petugas kesehatan maupun pasien. Pemahaman pasien terhadap penyakit dan kepatuhan pasien untuk memakai obat sangat penting dalam rangka mengontrol hipertensi. Pada umumnya kepatuhan pasien rendah bila pasien merasa tidak ada keluhan akibat penyakitnya. Namun apabila petugas kesehatan dapat menunjukkan komplikasi yang dapat diderita pasien, seperti ancaman kebutaan, diharapkan kepatuhan pasien dapat meningkat.

Identifikasi dan penegakan diagnosis retinopati hipertensi membutuhkan dokter 
spesialis mata untuk pemeriksaan pasien. Umumnya dokter spesialis mata tidak banyak bertugas di puskesmas. Kasus hipertensi dapat diselesaikan di fasilitas kesehatan primer seperti Puskesmas. Bila tidak dilakukan pemeriksaan lanjutan, maka angka retinopati hipertensi yang sesungguhnya di layanan kesehatan primer tidak diketahui.

Kesadaran pasien yang kurang mengenai pentingnya melakukan pemeriksaan mata secara rutin juga menyebabkan prevalensi retinopati hipertensi tidak diketahui. Peran aktif dokter sebagai lini terdepan dalam pelayanan kesehatan sangat penting untuk mencegah avoidable blindness. Puskesmas sebagai ujung tombak layanan kesehatan masyarakat terdepan dapat menjadi pintu deteksi dini dan screening awal retinopati hipertensi.

\section{TINJAUAN PUSTAKA}

Hipertensi atau darah tinggi adalah suatu keadaan dimana tekanan darah sistolik $\geq 140 \mathrm{mmHg}$ dan/atau tekanan darah diastolik $\geq 90 \mathrm{mmHg} .{ }^{1}$ Terdapat sedikit perubahan yang dikeluarkan oleh Joint National Committee (JNC) 8, antara lain pada pasien berusia 60 tahun ke atas, target tekanan darah sistolik adalah $<150 \mathrm{mmHg}$, dan target tekanan darah pada pasien dewasa dengan diabetes atau penyakit ginjal kronis menjadi $<140 \mathrm{mmHg}^{5}$ Komplikasi hipertensi dapat mengenai berbagai organ target seperti jantung, otak, ginjal, mata, dan arteri perifer. Komplikasi pada mata dapat berupa retinopati, optik neuropati, dan koroidopati. ${ }^{6-8}$

Retina adalah lapisan yang terletak di belakang bola mata. Lapisan ini mengubah cahaya menjadi sinyal saraf yang kemudian dikirim ke otak untuk interpretasi. Ketika tekanan darah terlalu tinggi, dinding pembuluh darah retina dapat menebal. Hal ini dapat menyebabkan pembuluh darah menjadi menyempit, yang kemudian menghambat darah sampai ke retina. Pada beberapa kasus, retina menjadi edema. Seiring berjalannya waktu, tekanan darah tinggi dapat menyebabkan kerusakan pada pembuluh darah retina, sehingga membatasi fungsi retina, memberikan tekanan pada nervus optikus, dan menyebabkan gangguan penglihatan. Kondisi ini disebut retinopati hipertensi. , $^{9}$ 
Patofisiologi terjadinya retinopati hipertensi adalah arteriol merespon peningkatan tekanan luminal dengan vasokonstriksi untuk mengurangi aliran darah. Kondisi patologi berkembang ketika peningkatan tekanan menyebabkan kerusakan endotel. Degenerasi otot polos arteriolar menyebabkan kerusakan endotelium sehingga terjadi kebocoran plasma ke dinding pembuluh darah. Pembekuan plasma di dalam dinding pembuluh darah menyebabkan penebalan dinding dan penyempitan lumen. Proses ini disebut nekrosis fibrin. ${ }^{4}$

Perdarahan retina terjadi ketika pembuluh darah yang nekrotik perdarahan ke nerve fiber layer (pendarahan flame shaped) atau inner retina (perdarahan dot blot). Cotton wool spot disebabkan oleh iskemik pada nerve fiber layer oleh karena nekrosis fibrin dan penyempitan lumen. Iskemik pada nerve fiber menyebabkan penurunan aliran axoplasmic, edema nervus, dan terutama opasifikasi yang halus. Eksudat terjadi belakangan, mengelilingi area perdarahan, sebagai hasil akumulasi lipid. Papilledema disebabkan oleh kebocoran dan iskemik arteriol yang memperdarahi diskus optikus yang mengalami nekrosis fibrin. Iskemia menyebabkan edem papil dan batas yang tidak tegas, sementara kebocoran menyebabkan perdarahan dan edem papil. ${ }^{4}$

Adapun klasifikasi Retinopati Hipertensi menurut Modified Scheie Classification yaitu: ${ }^{4}$ Grade 0: tidak ada perubahan

Grade 1: penyempitan arteri yang baru terdeteksi

Grade 2: penyempitan arterial yang ata dengan irregularitas fokal

Grade 3: grade 2 ditambah perdarahan retina dan/atau eksudat

Grade 4: grade 3 ditambah edem papil

\section{METODE}

Metode yang digunakan dalam pengabdian masyarakat ini adalah melalui penyuluhan dan pemberian layanan kesehatan berupa skrining retinopati hipertensi. Kegiatan dipersiapkan melalui pertemuan dengan pihak Puskesmas yang diwakili oleh 
kepala Puskesmas Dempo dan Merdeka. Tim dokter menjelaskan tentang prosedur pemeriksaan yang akan dilakukan, dan pihak Puskesmas mempersiapkan pasien dari masing-masing poliklinik sebanyak 75 orang pasien. Tim pelaksana kegiatan kemudian dibagi menjadi dua tim, masing-masing tim berjumlah tiga orang dokter spesialis mata yang disebar di dua Puskesmas tersebut.

Pada hari pemeriksaan, peserta dikumpulkan untuk mendapatkan penyuluhan untuk meningkatkan pengetahuan dan kesadaran akan pentingnya pemeriksaan tekanan darah tinggi, serta komplikasi yang dapat terjadi akibat peningkatan tekanan darah yang tidak terkontrol. Setelah itu, peserta menjalani pemeriksaan untuk mendeteksi kelainan retinopati hipertensi. Tahapan pemeriksaannya meliputi:

1. mempersiapkan perlengkapan, diantaranya Snellen Chart, funduskopi, dan midriatikum,

2. melakukan pemeriksaan tajam penglihatan pasien pada jarak enam meter dengan melihat Snellen Chart,

3. pasien diteteskan midriatikum untuk membantu evaluasi segmen posterior dengan menggunakan funduskopi,

4. melakukan rekap hasil pemeriksaan yang ditulis dalam bentuk tabel.

\section{HASIL DAN PEMBAHASAN}

Kegiatan pengabdian berjudul "Skrining retinopati hipertensi di layanan kesehatan primer di Palembang" dilaksanakan pada tanggal 11-14 November 2019 di Puskesmas Dempo dan Puskesmas Merdeka. Kegiatan dilaksanakan pukul 08.30 s/d 14.00 WIB total jumlah Pasien 150 Orang.

Kegiatan pengabdian masyarakat ini berlangsung lancar dan secara keseluruhan didapatkan respon peserta yang baik. Hal ini dapat diketahui dari hasil pengamatan selama kegiatan sedang berlangsung. Antusiasme peserta terlihat dari banyaknya pertanyaan yang 
diajukan oleh peserta saat penyuluhan, terutama mengenai komplikasi hipertensi khususnya komplikasi di mata.

Tabel 1. Karakteristik peserta kegiatan pengabdian masyarakat

\begin{tabular}{lll}
\hline Keterangan & $\mathrm{n}$ & $\%$ \\
\hline Retinopati Hipertensi & & \\
$\quad$ Ya & 23 & 15,3 \\
$\quad$ Tidak & 127 & 84,7 \\
Riwayat hipertensi pasien dengan retinopati hipertensi & & \\
$\quad 55$ tahun & 8 & 34,8 \\
$>5$ tahun & 15 & 65,2 \\
\hline
\end{tabular}

Pada kegiatan ini, didapatkan 23 pasien yang mengalami kelainan retinopati hipertensi. Sebagian besar dari pasien dengan retinopati hipertensi memiliki riwayat hipertensi lebih dari 5 tahun.

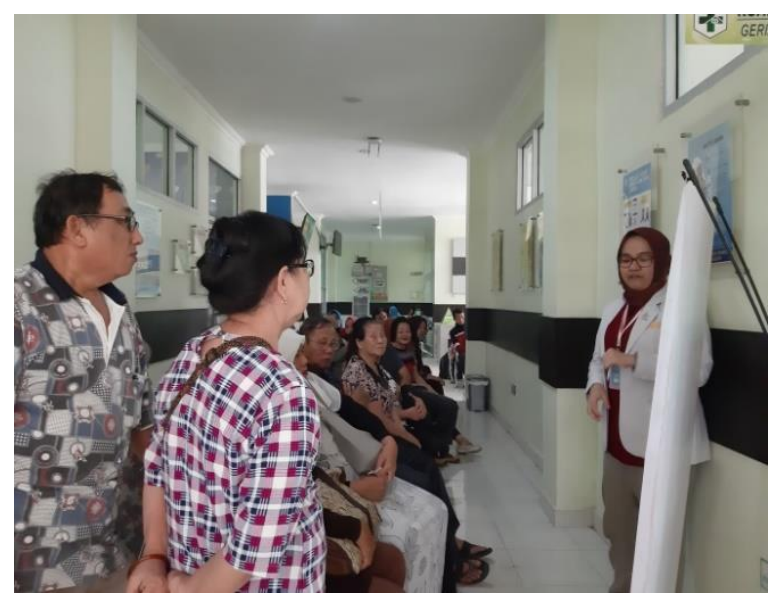

Gambar 1. Pemateri sedang menyampaikan materi

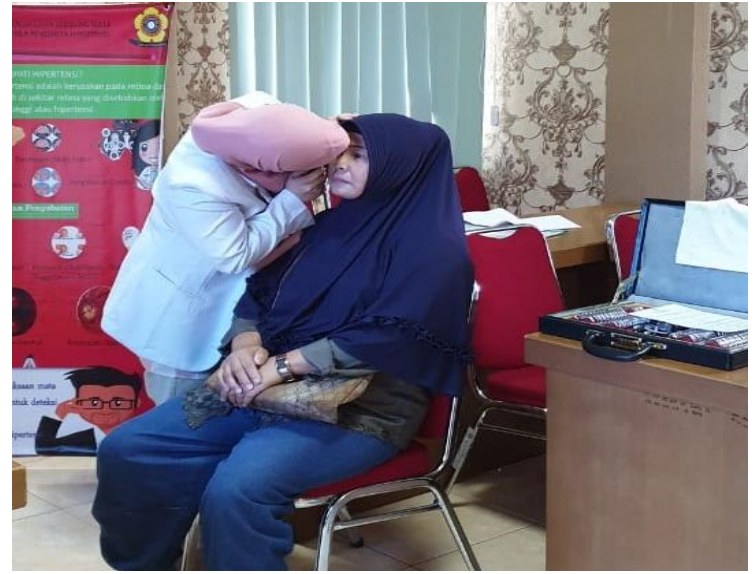

Gambar 2. Skrining retinopati hipertensi 


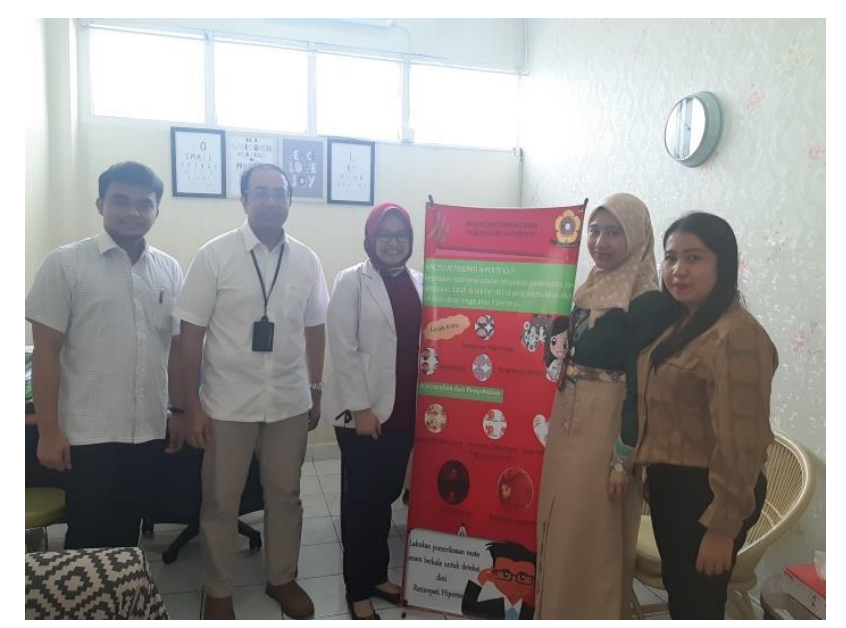

Gambar 3. Tim dokter dan banner sebagai media edukasi

\section{SIMPULAN}

Kegiatan pengabdian masyarakat ini berjalan dengan baik, dapat dilihat dari antusiasme peserta saat penyuluhan diadakan. Pada pemeriksaan, didapatkan pasien dengan retinopati hipertensi yang belum pernah terdeteksi sebelumnya. Kegiatan ini sebaiknya dapat ditindaklanjuti dari pihak layanan kesehatan primer seperti Puskesmas melalui edukasi rutin tentang retinopati hipertensi pada pasien dengan hipertensi, dan merujuk pasien ke dokter spesialis mata agar dapat dilakukan deteksi dini.

\section{Ucapan Terima Kasih}

Ucapan terimakasih kami tujukan kepada teman-teman sejawat dan stake holder yang telah membantu kegiatan ini, serta Fakultas Kedokteran Unsri yang telah membiayai kegiatan ini. Dana kegiatan berasal dari Anggaran DIPA Fakultas Kedokteran Universitas Sriwijaya No. SP DIPA-042.01.2.400953/2019.

\section{Referensi}

1. Alexander M. Hypertension [Internet]. 2019 [cited 2019 Feb 17].

2. Hasil utama Riskesdas 2018 [Internet]. Badan Penelitian dan Pengembangan Kesehatan Kementerian Kesehatan RI; 2018 [cited 2019 Sep 10].

3. Pusat Data dan Informasi Kementerian Kesehatan Republik Indonesia. Hipertensi 
[Internet]. 2014 [cited 2020 Sep 17].

4. McCannel CA. 2018-2019 BCSC (Basic and clinical science course), section 12: retina and vitreous [Internet]. American Academy of Ophthalmology. 2018 [cited 2019 Sep 18].

5. Muhadi. JNC 8: Evidence-based guideline penanganan pasien hipertensi dewasa. Cermin Dunia Kedokt. 2016;43(1): 54-9.

6. Hypertension [Internet]. 2019 [cited 2019 Sep 17].

7. Soenarta AA, Erwinanto, Mumpuni ASS, Barack R, Lukito AA, Hersunarti N, et al. Pedoman tatalaksana hipertensi pada penyakit kardiovaskular [Internet]. Perhimpunan Dokter Spesialis Kardiovaskular Indonesia. 2015 [cited 2019 Sep 17]. 16 p.

8. Rahajoe AU, Firdaus I, Maeza A, Kurniawan M, Kusmantono H, Ardiyani, et al. Pedoman teknis penemuan dan tatalaksana hipertensi [Internet]. Indonesia: Direktorat Pengendalian Penyakit Tidak Menular; 2013 p. 1-58.

9. Jeganathan VSE, Cheung N, Tay WT, Wang JJ, Mitchell P, Wong TY. Prevalence and risk factors of retinopathy in an Asian population without diabetes: The Singapore Malay eye study. Arch Ophthalmol. 2010;128(1): 40-5.

10. Oh KT. Ophthalmologic manifestations of hypertension: Acute and chronic changes to the eyes, assessment, treatment \& management [Internet]. 2018 [cited 2019 Sep 18]. 